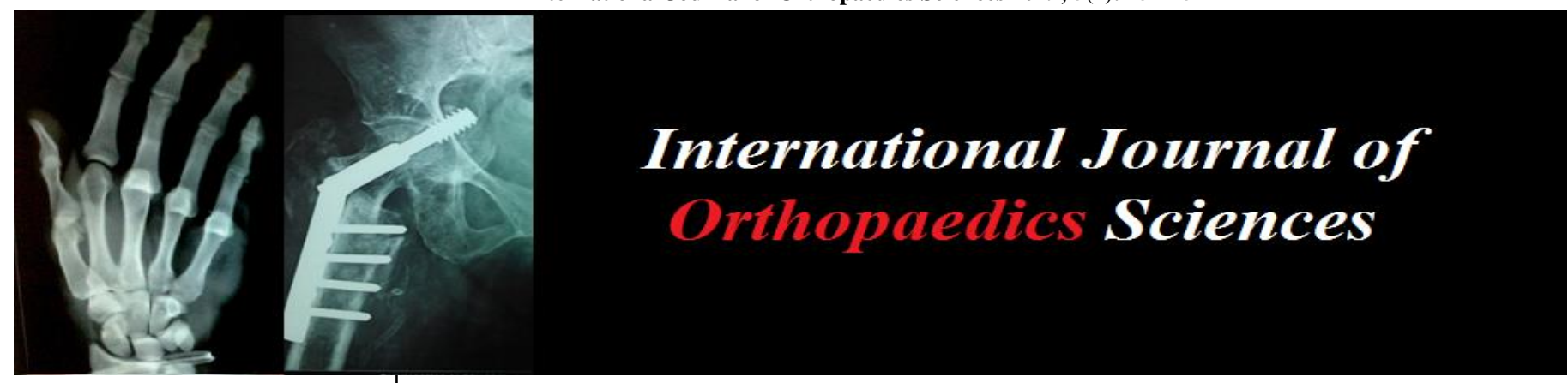

ISSN: 2395-1958

IJOS 2019; 5(2): 151-154

(C) 2019 IJOS

www.orthopaper.com

Received: 19-02-2019

Accepted: 23-03-2019

Pratik Agarwal

Fellow of Arthroplasty, Ganga Hospital, Coimbatore, Address: Abhishek Steel, Mangal Pandey Road, Siliguri, West Bengal,

India

\section{Abir Ghosh}

Assistant Professor, IPGME\&R, Kolkata, West Bengal, India

\section{Arnab Karmakar}

Assistant Professor, IPGME\&R, Kolkata, Address:- Dept of orthopaedics, $2^{\text {nd }}$ floor Ronald ross building, IPGME\&R, 244 AJC Bose Road, Kolkata, West Bengal, India

\section{Correspondence}

Abir Ghosh

Assistant Professor, IPGME\&R,

Kolkata, West Bengal, India

\section{Arnab Karmakar}

Assistant Professor, IPGME\&R,

Kolkata, Address:- Dept of orthopaedics, $2^{\text {nd }}$ floor Ronald ross building, IPGME\&R, 244 AJC Bose Road, Kolkata, West Bengal, India

\section{Experiences of intramedullary fixation of displaced clavicle fractures in young adults}

\author{
Pratik Agarwal, Abir Ghosh and Arnab Karmakar
}

DOI: https://doi.org/10.22271/ortho.2019.v5.i2c.28

\section{Abstract}

Background: Incidence of fracture shaft of clavicle is increasing in young population due to increase incidence of road traffic accident. Conventionally plate and screw fixation has been the choice, but to avoid complications like soft tissue problem, hardwire prominence, nonunion etc, a less invasive method like intramedullary fixation is desirable.

Materials and Methods: This prospective study was conducted in orthopaedic Deptt. of IPGMER and SSKM Hospital, Kolkata during January 2015 to August 2017 on 30 adult patients with fresh closed fractures of mid shaft of clavicle. Patients with open fractures, pathological fractures, and grossly comminuted fractures were excluded. All the nails were introduced through medial side of clavicle under fluoroscopic guidance and open reduction with minimum tissue dissection when closed reduction not possible. All patients were follow up for one and half year for results in terms of time to union, operative complications, functional score etc.

Results: All the fractures united within a reasonable period with good functional result in respect to constant-murley shoulder score with less complications.

Conclusion: Intramedullary fixation, like TENS nail is a good viable option in displaced midshaft fracture of clavicle.

Keywords: clavicle, displaced, intramedullary

\section{Introduction}

Fracture of clavicle comprises about $2.6 \%$ of all fractures, of which $80-85 \%$ occurs in middle third ${ }^{[1,2,3]}$. Road traffic accidents now become a major cause of it specially in young adults. Closed midshaft fracture of clavicle has been conventionally treated by conservative method, but long time application of brace, nonunion, malunion, decreased shoulder endurance and unacceptable cosmetic look result in favour for internal fixation. Open reduction with plate fixation is a standard acceptable method of treatment, but it has also pitfalls like wound complications, hardwire prominence, infection, implant failure, refracture etc. in this context, intramedullary fixation with mini open approach with elastic TENS nail is a good option. This would mitigate many pitfalls of conservative and operative approach of plate fixation. Moreover due to stress distribution and micro movement, early callous formation and healing of fracture occur with well alignment. The aim of our study is to see the rate of union, functional recovery of shoulder and complication of intramedullary fixation of closed displaced mid shaft fracture clavicle in young adults.

\section{Materials and Methods}

This institution based longitudinal prospective study was conducted in Orthopaedic department of IPGMER and SSKM Hospital from January 2015 to August 2017. Total 30 young patients of 18-40 years of age group including 22 male and 8 female were include in the study after proper counseling explaining all the pros and cons of the procedure and institutional ethical clearance. Patients with closed midshaft fracture clavicle (type-1, according to Allman classification system) of less than three weeks duration are included in the study. Those with open fracture, more than three weeks duration, paediatric and geriatric age group, pathological fracture, clavicle fracture associated with other fracture of the ipsilateral limb are excluded from the study. 
We have used titanium elastic nails (TENS) for all fractures. Patients were given general anesthesia in supine position and Nails were introduced one $\mathrm{cm}$ lateral to sternoclavicular joint. Closed reduction were done with percutaneous reduction forceps when possible under fluoroscopic guidance, otherwise reduction was done with mini incision. Then nail was introduced with an introducer and progressed through the fracture until just medial to acromioclavicular joint. After fracture site compression nail cut short medially just beneath the skin. Gentle active motion started in pain free range on $5^{\text {th }}$ post op day that gradually progressed to full range.

\section{Results and analysis}

We have studied 30 patients of mean age- 28.8 years of result and outcome of intramedullary fixation of fracture mid shaft clavicle. Minimum duration of injury was 2 days and maximum 8 days with a mean of 4.28 days. Minimum surgical time was 30 minutes and maximum 70 minutes with an average 46.4 minutes. Outcome was measured in respect of clinical evaluation of shoulder function by constant-murley (CMS) score, radiological evidence of fracture union and complication. Follow up evaluation done at four weeks postoperative period, three, six and finally at nine month. For statistical analysis data were entered into a Microsoft excel spreadsheet and then analyzed by SPSS 20.0.1 and Graph Pad Prism version 5. Data have been summarized as mean and standard deviation for numerical variables and count and percentages for categorical variables. The median and the interquartile range have been stated for numerical variables that are not normally distributed.

\section{Result}

Table 1: Showing distribution of mean time of fracture union (in months) of study group

\begin{tabular}{|c|c|c|c|c|c|}
\hline Number & Mean & SD & Minimum & Maximum & Median \\
\hline 30 & 3.5000 & .4537 & 3.0000 & 4.0000 & 3.5000 \\
\hline
\end{tabular}

All the fractures were united within a reasonable period, with a mean of 3.5 months. Mean postoperative hospital stay of all patients was 5.7 days.

Table 2: Showing distribution of mean post-op hospital stay (in days) of study group

\begin{tabular}{|c|c|c|c|c|c|}
\hline Number & Mean & SD & Minimum & Maximum & Median \\
\hline 30 & 5.7222 & 2.2177 & 3.0000 & 10.0000 & 5.0000 \\
\hline
\end{tabular}

All the nails were removed with a minimum period of 122 days and maximum 141 days and a mean 132.4 days.

\section{Result}

Table 3: Showing Distribution of Final follow-up Constant Murley score of study group

\begin{tabular}{|c|c|c|}
\hline Constant-Murley score & Frequency & Percent \\
\hline Excellent & 20 & $66.7 \%$ \\
\hline Good & 10 & $33.3 \%$ \\
\hline Total & 30 & $100.0 \%$ \\
\hline
\end{tabular}

At the final follow up 20 patients have excellent score and 10 had good score according to CMS criteria. We have found no major complications except one had superficial skin infection, which was subsequently healed after antibiotic, and dressing and chronic pain at insertion site in two patients that did not affect lifestyle.

\section{Result}

Table 4: Showing distribution of complications of study group 49

\begin{tabular}{|c|c|c|}
\hline Complications & Frequency & Percent \\
\hline Chronic Pain at insertion site & 4 & $13.3 \%$ \\
\hline None & 24 & $80 \%$ \\
\hline Superficial infection & 2 & $6.6 \%$ \\
\hline Total & 30 & $100.0 \%$ \\
\hline
\end{tabular}

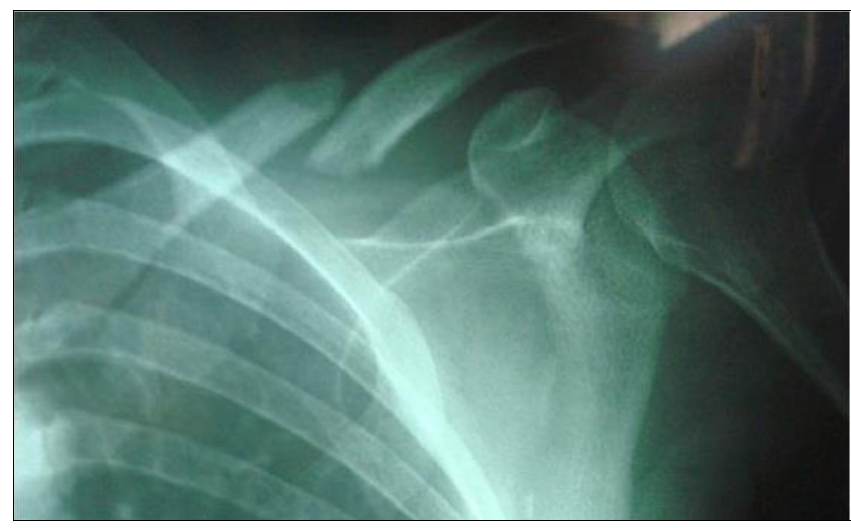

Fig 1: Preoperative $x$-rays of fracture midshaft clavicle.

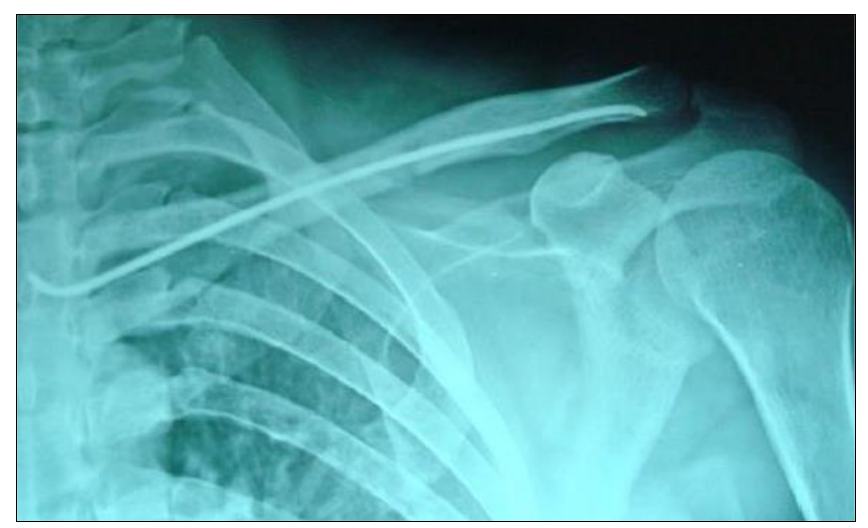

Fig 2: Three month post-op x-ray of same patient. Fracture united.

\section{Discussion}

Conservative treatment and ORIF is the mainstay of treatment of midshaft fracture clavicle. But due to several complications as stated earlier, a less invasive approach is an attractive alternative treat option like mini incision intramedullary fixation. The distribution of sex in study group was $77.8 \%$ of males and $22.2 \%$ of females. The distribution of side of fracture in study group was $66.7 \%$ of left side and $33.3 \%$ of right side. A study titled: Epidemiology of clavicle fractures: Postacchini et al. ${ }^{[4]}$ conducted study on 535 isolated clavicle fractures and found that incidence of clavicle fractures is more in males and fracture are more common in left side. Male patients are higher in number, may be they are more involved in road traffic accident. In our study group all the fractures were united with TENS nail with mean time of healing was 3.5 month.

A study titled: Mid-shaft clavicular fracture and titanium elastic intramedullary nailing by Mishra et al. ${ }^{[5]}$ Average time taken for full clinical and radiological union was two and a half months (with minimum one and a half months to maximum three months).

A study titled: Clinical outcomes of mid clavicular fractures treated with titanium elastic nails by Yun-FengChen et al. ${ }^{[6]}$ a mean follow-up of 14.5 months (range 7-24 months) revealed radiographic fracture union in all 41 patients with an average clinical healing time of 2.2 months. So 
healing time was comparable to other studies. $80 \%$ of the fractures united without any complications, while the rest $20 \%$ developed minor complications like chronic pain at the insertion site (13.3\%) and superficial infection (6.6\%).

A study titled: Midshaft clavicular fracture and titanium elastic intramedullary nailing in 79 patients by Mishra et al seven patients $(9.5 \%)$ complained for skin irritation and three patients $(4.1 \%)$ had a wound (superficial infection) at the medial end of clavicle at the nail insertion site and after nail removal (done earlier after three month of full union), healed by secondary intention. In our study Functional shoulder outcome in respect to constant-murley shoulder score ${ }^{[15]}$ at final follow-up was an average 90.5, with maximum being 100 and minimum being 80. Functional outcome are less complications in our study may be due to young age group, closed fracture, early surgery, less tissue dissection, early patient discharge and rehabilitation programme. comparable to other study done. Good functional score and

Table 5: Table show shoulder function and CMS

\begin{tabular}{|c|c|c|}
\hline S.N. & Study & Shoulder Function in terms of CMS \\
\hline 1. & F. Hartmann et al. ${ }^{[7]}$ & CMS was $95.3+/-3.9$ \\
\hline 2. & Yun-Feng Chen et al. & CMS was 95.2(range $86.5-97.0)$ \\
\hline 3. & Zhang et al. ${ }^{8]}$ & CMS was $97.0+/-4.2$ \\
\hline 4. & Mishra et al. & CMS was $96.8(\max =100 ; \min =92)$ \\
\hline 5. & This study & CMS $90.5(\max =100 ; \min =80)$ \\
\hline
\end{tabular}

The limitations of the study included the absence of a comparison group treated with open reduction and plate fixation for comparison of effectivity of such a treatment modality. We conclude that intramedullary fixation with TENS in fracture shaft of clavicle is a viable alternative modality of treatment as this method is promising due to affordability, load sharing property, shorter hospital stay, quick pain relief, early return to work and easy implant removal under local anaesthesia as an outpatient department procedure. In the future an attempt to overcome the limitations of the study may prove fruitful in treating these sorts of fractures.
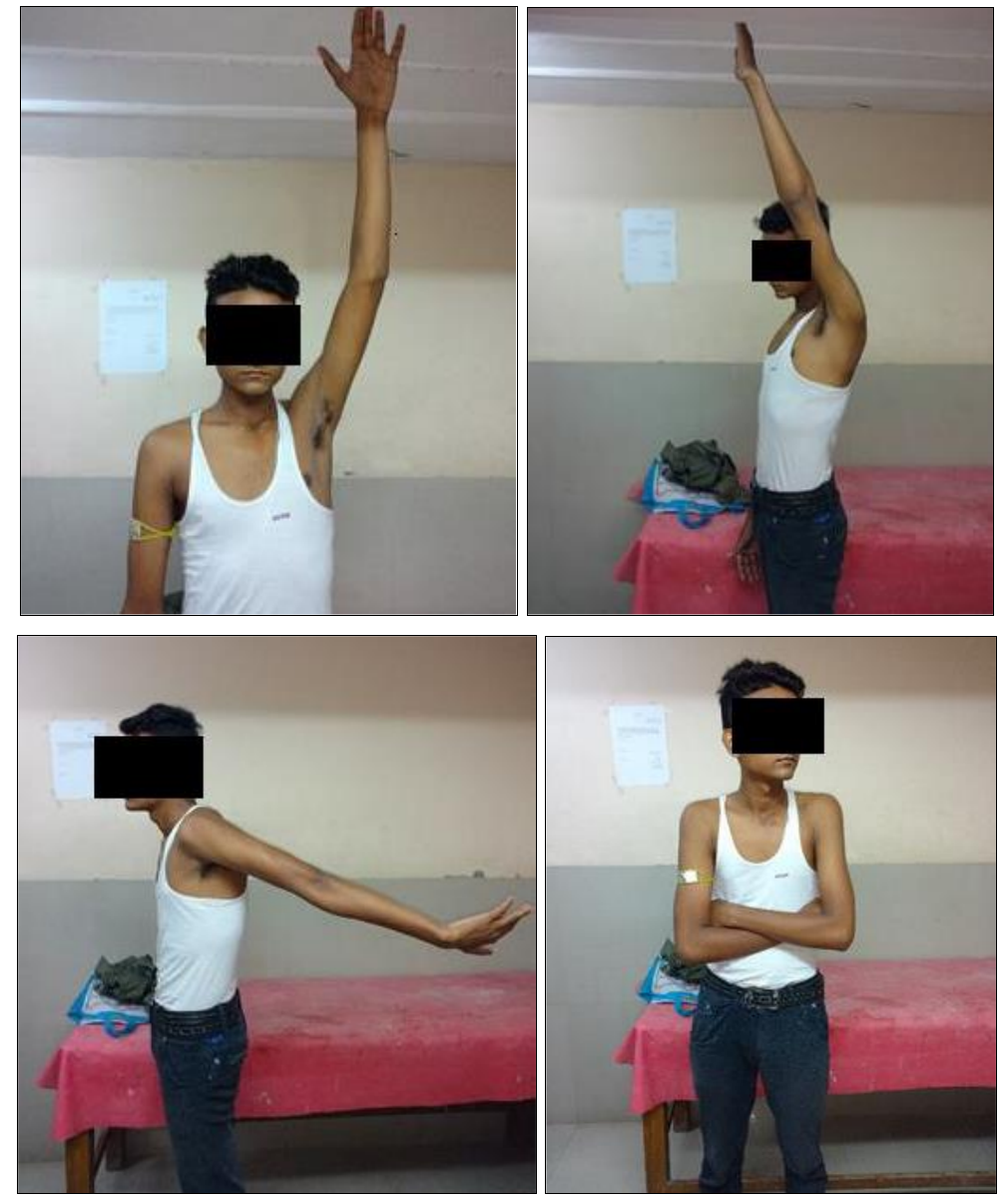

Fig 3

\section{References}

1. Rockwood and Green's fractures in Adults 8th international edition.

2. Campbell's operative orthopaedics 12th edition.

3. Stanley D et al. The Mechanism of clavicular fracture, a clinical and biomechanical analysis. J Bone Joint Surg [Br]. 1988; 70-B:461-464.

4. Postacchini F, Gumina S, Santis P, Albo F. Epidemiology of clavicle fractures. J Shoulder Elbow Surg. 2002; 11:452-456.

5. Pankaj Kumar Mishra, Anuj Gupta, Suresh Chandra Gaur. Midshaft clavicular fracture and titanium elastic intramedullary nail. Journal of Clinical and Diagnostic Research. 2014; 1:129-132.

6. Yun-Feng-Chen et al. Clinical outcomes of mid clavicular fractures treated with titanium elastic nails Can J Surg. 2010; 3(6):379-84.

7. Hartmann F, Hessmann MH, Gercek E, Rommens PM. Elastic Intra-medullary Nailing of Midclavicular Fractures Acta Chir Belg. 2008; 108:428-32.

8. Zhang et al. Meta-analysis of plate fixation versus intramedullary fixation for the treatment of mid-shaft clavicle fractures. Scand J Trauma Resusc Emerg Med. 2015, 23-27. 
9. Muller MC, Burger C, Florczyk A et al. Elastic titanium nails in minimally invasive osteosynthesis for midclavicular fractures. Chirurg. 2007; 78:349-355.

10. Boehme D, Curtis RJ Jr, DeHaan JT et al. Nonunion of fractures of the mid-shaft of the clavicle. Treament with a modified Haigie intramedullary pin and autogenous bone grafting. J Bone Joint Surg Am. 1991; 73(8):1219-1226.

11. Systemic review of 2144 fractures of shaft clavicle: Zlowodzki, Michael, Zelle; Journal of orthopaedic trauma. 2005; 19(7):504-507.

12. Comparison between non- operative treatment and open intramedullary fixation: Grassi; Federico A Fabi. Journal of trauma-injury, infection and critical care. 2001; 50(6):1096-1100.

13. Chuang TY, Ho WP, Hsieh PS et al. Closed reduction and internal fixation for acute midshaft clavicular fractures using cannulated screws. J Trauma. 2006; 60(6):1320-1321.

14. Judd DB, Pallis MP, Smith E et al. Acute operative stabilization versus nonoperative management of clavicle fractures. Am J Orthop. 2009; 38(7):341-345.

15. Enneking TJ, Hartlief MT, Fontijine WP. Rushpin fixation for midshaft clavicular nonunions: Good results in 13/14 cases. Acta Orthop Scand. 1999; 70(5):514-516.

16. Constant C, Murley A. A clinical method of functional assessment of the shoulder Clin Orthop Rel Res. 1985; 214:160-64. 